\title{
Effect of Mixing Method on the Mixing Degree during the Preparation of Triturations
}

\author{
Hitoshi NaKamura, ${ }^{a}$ Yoshitsugu Yanagihara, ${ }^{a}$ Hiroko SeKiguchi, ${ }^{b}$ Fusao Komada, ${ }^{c}$ \\ Haruno KaWABATA, ${ }^{c}$ Michiteru OHTANI, ${ }^{b}$ Yukiya SaItoh,,$^{c}$ Satoru KariYa, ${ }^{b}$ \\ Hiroshi SUZUKI, ${ }^{a}$ Katsuyoshi UCHINO, ${ }^{b}$ and Tatsuji IGA ${ }^{*, a}$ \\ Department of Pharmacy, The University of Tokyo Hospital, Faculty of Medicine, The University of Tokyo, ${ }^{a}$ \\ 7-3-1 Hongo, Bunkyo-ku, Tokyo 113-8655, Japan, Department of Hospital Pharmacy, Tokyo Postal \\ Service Agency Hospital, ${ }^{b}$ 2-14-23 Fujimi, Chiyoda-ku, Tokyo 102-8798, Japan and \\ Department of Drug Informatics, Faculty of Pharmaceutical Sciences, \\ Jyosai University, ${ }^{c}$ 1-1 Keyakidai, Sakado, Saitama 350-0295, Japan
}

(Received September 3, 2003; Accepted December 10, 2003)

\begin{abstract}
By using lactose colored with erythrocin, we investigated the effects of mixing methods on mixing degree during the preparation of trituration with a mortar and pestle. The extent of powder dilution was set to 4 to 64 fold in the experiments. We compared the results obtained by using two methods: (1) one-step mixing of powders after addition of diluents and (2) gradual mixing of powders after addition of diluents. As diluents, we used crystallized lactose and powdered lactose for the preparation of trituration. In the preparation of 64-fold trituration, an excellent degree of mixing was obtained, with CV values of less than $6.08 \%$, for both preparation methods and for the two kinds of diluents. The mixing of two kinds of powders whose distributions of particle sizes were similar resulted in much better degree of mixing, with CV values of less than 3.0\%. However, the concentration of principal agents in 64-fold trituration was reduced by $20 \%$ due to the adsorption of dye to the apparatus. Under conditions in which a much higher dilution rate and/or much better degree of dilution was required, it must be necessary to dilute powders with considering their physicality and to determine the concentrations of principal agents after the mixing.
\end{abstract}

Key words—_triturations; mixing degree; mixing method

\section{INTRODUCTION}

The degree of mixing in trituration is affected by many factors, including the physicality and mixing ratio of the principal agents and diluents, the mixing conditions and the kind of blender. Many studies using V-type blender have been performed to determine the effects of various factors on mixing degree. ${ }^{1-4)}$ However, there has been little investigation of the effects of various factors on the degree of mixing using a mortar and pestle, which are frequently used in hospitals and general pharmacies. It has been reported that uniform mixing is achieved after $60-80$ rotations in the case of preparation of $5.0-30.0 \mathrm{~g}$ of powdered medicine if the gravity of the principal agents and that of diluents are similar..$^{5-7)}$ Although an excellent degree of mixing is achieved when powders with similar particle sizes are used, it has been reported that the mixing degree of powders with different particle sizes is unsatisfactory. It has also

e-mail: igat-tky@umin.ac.jp been reported that the mixing degree is improved by riddling the powders through dispensing sieves before mixing. ${ }^{8)}$ For trituration of small amounts of principal agents with diluents, a gradual mixing method is recommended up to the 10th edition of the Japanese Guidelines for Dispensation. ${ }^{9,10)}$ In the gradual mixing method, the same amount of diluents is added to the principal agent, and they are mixed to prepare a 2fold trituration. Then the same amount of diluents as that of the 2-fold trituration is added to prepare a 4fold trituration, and this procedure is repeated until the required dilution has been obtained. However, since no theoretical background has been provided for the gradual mixing method described in the Japanese Guidelines for Dispensation, various methods are used for triturations in pharmacies.

In the present study, we investigated the effects of various mixing methods on the mixing degree of powdered lactose colored with erythrocin, a food coloring agent, by using a mortar and pestle, which are generally used for dispensation. We also compared the mixing degrees of powdered lactose and crystallized 
lactose.

\section{MATERIALS AND METHODS}

Materials Lactose powder (lot number 099208) and crystallized lactose (lot number 084RRR) were purchased from Yoshida Seiyaku, Co., Ltd., Tokyo, Japan and Merukuhoei Co., Ltd., Tokyo Japan, respectively. Erythrocin (lot number GG41HH) from Tokyo Kasei Kogyo, Co., Ltd., Tokyo, Japan was used in the present study.

\section{Preparation of Colored Lactose Twenty grams of} $98.0 \mathrm{~g}$ of lactose powder was transferred to a glass mortar, and $2.0 \mathrm{~g}$ of erythrocin dissolved in $5 \mathrm{ml}$ of distilled water was added to the mortar and mixed well. After addition of the remaining lactose powder, the slurry was mixed until it became homogeneous and was then riddled through a 32-mesh dispensing sieve (screen size of $500 \mu \mathrm{m}$ ). After drying at $60^{\circ} \mathrm{C}$ for $1 \mathrm{~h}$ using a circulating warm-air dehydrator, the resulting pellet was sieved through a 100 -mesh dispensing sieve (screen size of $149 \mu \mathrm{m}$ ).

Preparation of Diluents The effects of mixing methods on the mixing degree was investigated after adjusting the particle sizes of the principal agent (colored lactose) and diluents. For this purpose, we prepared powdered lactose by the same method as described in the previous section. We also compared the results obtained by using crystallized lactose, which is frequently used in hospitals and community pharmacies, with the results obtained by using powdered lactose.

Determination of Particle Size The distribution of particle sizes in colored lactose and powdered lactose prepared as diluents were determined by riddling the powder through 32-, 42-, 60-, 80-, 100-, 150- and 200-mesh prescription sieves, whose screen sizes are $500,350,250,177,149,105$ and $74 \mu \mathrm{m}$, respectively. Particle size distribution was also determined by using a laser diffraction particle analyzer (Sald-3000, Shimadzu Co., Ltd.) under dry conditions. Flexibility of $1.7-0.20 \mathrm{i}$ was used because these absolute values are used for the measurement of powders. For each specimen, the particle sizes were measured in three independent determinations.

Methods of Mixing A china mortar with an outer diameter of $10 \mathrm{~cm}$ and depth of $5 \mathrm{~cm}$ (Nikkatou Seiyaku, Tokyo, Japan) was used. The mortar was held and rotated by the left hand, and the pestle was rotated by the right hand spirally in the direction op- posite to that of the rotation of the mortar. For the mixing, 10 clockwise rotations followed by 10 anticlockwise rotations were repeated three times, the mortar thus being rotated 60 times. In some cases, the mixed powder was removed from the mortar and then added to the mortar for additional 20 rotations. Rotation was performed at a constant rate (60 rotations/ $30 \mathrm{~s})$.

The following two methods were used for the mixing: (1) colored lactose powder and the required amount of diluents to prepare the triturations were added together to the mortar, and the mortar and pestle were rotated 60 or 80 times (one-step mixing method) and (2) after adding the same amount of diluents to colored lactose, they were mixed to prepare a 2 -fold trituration. Then the same amount of diluents of the 2-fold trituration was added to the mortar to prepare a 4-fold trituration, and this procedure was repeated until the required dilution had been obtained (gradual mixing method).

We prepared 4-, 8-, 16-, 32- and 64-fold triturations in the present study. For one-step mixing, the colored lactose and diluents were simultaneously added to the mortar, and the mortar and pestle were rotated for 60 or 80 times to prepare the $16 \mathrm{~g}$ triturations. For gradual mixing, the following procedures were used for the 4-fold trituration. Four grams of diluents was added to $4 \mathrm{~g}$ of colored lactose, and the mortar was rotated 60 times to produce a 2 -fold trituration of $8 \mathrm{~g}$. Then $8 \mathrm{~g}$ of diluents was added, and the mortar was rotated 60 times to produce $16 \mathrm{~g}$ of a 4-fold trituration. In the same manner, a 64-fold trituration was prepared as follows. After adding $0.125 \mathrm{~g}$ of colored lactose and $0.125 \mathrm{~g}$ of diluents to the mortar, the mortar was rotated 60 times to obtain $0.250 \mathrm{~g}$ of a 2 -fold trituration. Then $0.250 \mathrm{~g}$ of diluents was added to this 2 -fold trituration, and the mortar was rotated 60 times to produce $0.50 \mathrm{~g}$ of a 4 -fold trituration. This procedure was repeated to prepare a 64-fold trituration.

Estimation of Mixing Degree After the mixing, 1.0-g specimens were randomly taken from three portions of the mixed powder to determine the concentration of erythrocin. Each specimen was dissolved in distilled water to obtain a solution of $10 \mathrm{ml}$. The absorption at the wavelength of $524 \mathrm{~nm}$ was determined in a spectrophotometer (UV-160, Shimadzu Co., Ltd., Kyoto, Japan).

Assuming that the contents of the principal agents 
in the triturations are distributed according to the normal probability distribution, the CV value is estimated as $6.08 \%$ under conditions in which $90 \%$ of the powder fraction contains $100 \pm 10 \%$ of the expected amount of the major agent. ${ }^{11)}$ Therefore, the mixing degree was judged as excellent if the $\mathrm{CV}$ value of three determinations of erythrocin concentration in each preparation was less than $6.08 \%$.

Statistical Analysis ANOVA was performed to determine the significance of the difference between the results obtained by using the two methods and that between results obtained by using powdered lactose and crystallized lactose. The statistical significance was judged at the level of $p<0.05$. Cluster analysis was performed with StatisticaTM (StatSoft Japan Inc., Tokyo, Japan) using the Euclidean distance and Ward method as an aggregation algorithm and a cluster rule, respectively. ${ }^{12,13)}$

\section{RESULTS}

Distribution of Particle Sizes By using sieves with mesh sizes of $74-500 \mu \mathrm{m}$, it was revealed that the $d_{50}$ values of colored lactose and powdered lactose prepared in this study were 54 and $74 \mu \mathrm{m}$, respectively (Table 1$)$. The values of median diameters $\left(d_{50}\right)$ calculated from the results of determinations using a laser diffraction particle analyzer for the original and powdered lactose were $48.3+2.9$ and $54.0+3.2 \mu \mathrm{m}$, respectively (Table 2 ).

Variation in Principal Agent Concentrations in the Triturations The variation of erythrocin concentrations in powdered medicines prepared under various conditions are shown in Fig. 1. All CV values were less than $6.08 \%$ for both powdered lactose and crystallized lactose samples and for the two mixing methods. When powdered lactose is used, the CV value was less than $3 \%$ for the one-step mixing method followed by rotation 60 or 80 times and for the gradual mixing method. The use of crystallized lactose gave maximum CV values of $4.5-5.9 \%$ for the two mixing methods.

The results of repeated analysis of the $\mathrm{CV}$ value of

Table 1. Distribution of Particle Sizes of Colored and Powdered Lactose Evaluated with Sieves

\begin{tabular}{cccc}
\hline \hline \multirow{2}{*}{ Ssreen size } & Mesh number & \multicolumn{2}{c}{ Percentage remained \pm S.D. } \\
\cline { 3 - 4 } & & Colored lactose & Powdered lactose \\
\hline $500 \mu \mathrm{m}$ & 32 mesh & $0.00 \pm 0.00$ & $0.00 \pm 0.00$ \\
$350 \mu \mathrm{m}$ & 42 mesh & $0.20 \pm 0.17$ & $0.90 \pm 0.30$ \\
$250 \mu \mathrm{m}$ & 60 mesh & $0.49 \pm 0.04$ & $0.10 \pm 0.10$ \\
$177 \mu \mathrm{m}$ & 80 mesh & $0.26 \pm 0.29$ & $0.72 \pm 0.41$ \\
$149 \mu \mathrm{m}$ & 100 mesh & $0.13 \pm 0.23$ & $0.89 \pm 1.54$ \\
$105 \mu \mathrm{m}$ & 150 mesh & $14.00 \pm 0.60$ & $23.30 \pm 3.00$ \\
$74 \mu \mathrm{m}$ & 200 mesh & $15.20 \pm 1.00$ & $23.60 \pm 5.00$ \\
\hline \multicolumn{2}{c}{ Estimated $d_{50}(\mu \mathrm{m})$} & $53.52 \pm 0.62$ & $73.69 \pm 6.51$ \\
\hline
\end{tabular}

The fraction of powders trapped by sieves was examined in three independent determinations. The results are given as the percent of the applied amount. $69.7 \pm 0.6 \%$ and $50.5 \pm 5.5 \%$ of the colored lactose and powdered lactose were passed through 200 mesh sieves. The $d_{50}$ values were estimated from the intersecting points of the cumulative undersize distribution and cumulative residue distribution curves obtained by fitting the data described in this table.

Table 2. Particle Sizes of Colored and Powdered Lactose Evaluated in a Laser Diffraction Particle Analyzer

\begin{tabular}{lcc}
\hline \hline & Colored lactose & Powdered lactose \\
\hline Average article size $(\mu \mathrm{m})$ & $34.8 \pm 3.9$ & $28.0 \pm 4.3$ \\
$d_{10 \%}(\mu \mathrm{m})$ & $10.9 \pm 4.1$ & $5.5 \pm 8.8$ \\
$d_{50 \%}(\mu \mathrm{m})$ & $48.3 \pm 2.9$ & $54.0 \pm 3.2$ \\
$d_{90 \%}(\mu \mathrm{m})$ & $95.4 \pm 1.0$ & $83.6 \pm 11.2$ \\
\hline
\end{tabular}

The distribution of particle sizes of powders was determined in a laser diffraction particle analyzer. The results are given as the mean \pm S.D. of three independent determinations. 

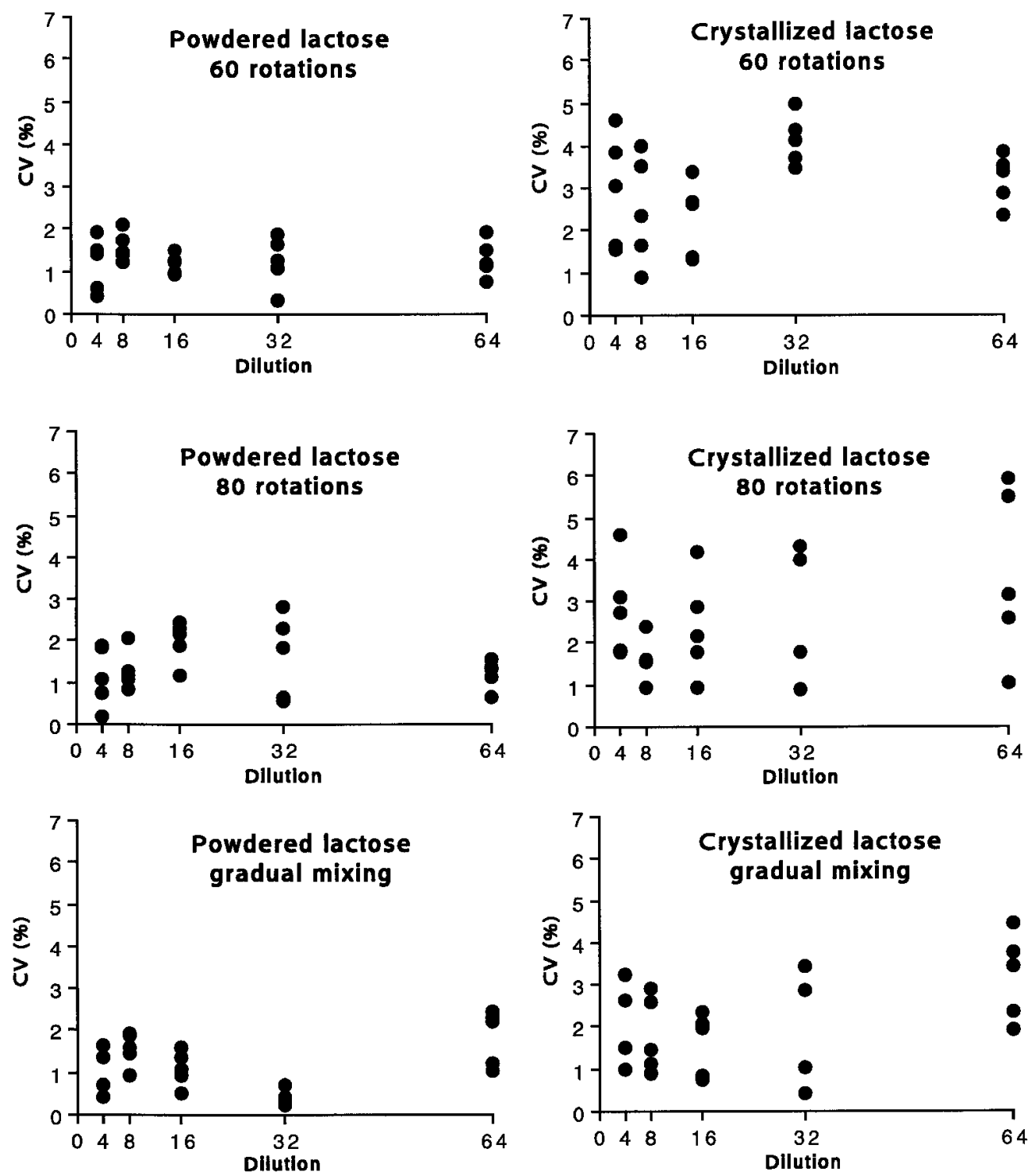

Fig. 1. CV Values of the Mixing Degree after the Mixing of Powdered and Crystallized Lactose by the One-step and Gradual Mixing Methods

Triturations of lactose colored with erythrocin were prepared using powdered and crystallized lactose. After mixing, specimens were taken from three portions of the mixed powder to determine the concentrations of erythrocin. Each point represents the CV value of three determinations for each preparation.

the mixing degree of powdered lactose and crystallized lactose are summarized in Table 3. When powdered lactose samples were compared, the difference between the mixing degrees by using the one-step and the gradual mixing methods and the mixing degrees obtained after 60 rotations and 80 rotations were minimal. In contrast, in the comparison of powdered and crystallized lactose samples, there were significant differences between the mixing degrees for both the one-step mixing followed by 60 times rotation and gradual mixing (shaded area in Table 3 ).

Cluster analysis indicated that the mixing degree can be classified into five clusters (clusters A-E) de- pending on the method of mixing and the kinds of diluents (Fig. 2). In this analysis, we have performed the cluster analysis for each data set which are shown in Fig. 1, and the data sets which resemble each other were put together to form five clusters (Fig. 2). The results are summarized in Table 4: cluster A consists of one-step mixing with 60 rotations and gradual mixing of crystallized lactose, clusters B consists of onestep mixing of crystallized lactose and gradual mixing of powdered lactose, cluster $\mathrm{C}$ consists of one-step mixing of crystallized lactose, cluster D consists of one-step mixing of powdered lactose, and cluster E consists of one-step and gradual mixing of powdered 
Table 3. Difference in Mixing Degree Depending on the Mixing Methods and the Kinds of Diluents

\begin{tabular}{|c|c|c|c|c|c|c|c|c|}
\hline \multirow{3}{*}{$\begin{array}{l}\text { Kind of } \\
\text { diluents }\end{array}$} & & & \multicolumn{3}{|c|}{ Powdered lactose } & \multicolumn{3}{|c|}{ Crystallized lactose } \\
\hline & \multirow{2}{*}{$\begin{array}{l}\text { Mixing } \\
\text { method }\end{array}$} & & \multicolumn{2}{|c|}{ One-step mixing } & \multirow{2}{*}{$\begin{array}{c}\begin{array}{c}\text { Gradual } \\
\text { mixing }\end{array} \\
\begin{array}{c}60 \\
\text { rotations }\end{array}\end{array}$} & \multicolumn{2}{|c|}{ One-step mixing } & \multirow{2}{*}{$\begin{array}{c}\begin{array}{c}\text { Gradual } \\
\text { mixing }\end{array} \\
\begin{array}{c}60 \\
\text { rotations }\end{array}\end{array}$} \\
\hline & & $\begin{array}{l}\text { Number of } \\
\text { rotations }\end{array}$ & $\begin{array}{c}60 \\
\text { rotations }\end{array}$ & $\begin{array}{c}80 \\
\text { rotations }\end{array}$ & & $\begin{array}{c}60 \\
\text { rotations }\end{array}$ & $\begin{array}{c}80 \\
\text { rotations }\end{array}$ & \\
\hline \multirow{3}{*}{$\begin{array}{l}\text { Powdered } \\
\text { lactose }\end{array}$} & \multirow{2}{*}{$\begin{array}{c}\text { One-step } \\
\text { mixing }\end{array}$} & $\begin{array}{c}60 \\
\text { rotations }\end{array}$ & - & 1 & 2 & 4 & 2 & 4 \\
\hline & & $\begin{array}{c}80 \\
\text { rotations }\end{array}$ & & - & 3 & 4 & 4 & 4 \\
\hline & $\begin{array}{c}\text { Gradual } \\
\text { mixing }\end{array}$ & $\begin{array}{c}60 \\
\text { rotations }\end{array}$ & & & - & 2 & 2 & 4 \\
\hline \multirow{3}{*}{$\begin{array}{c}\text { Crystallized } \\
\text { lactose }\end{array}$} & \multirow{2}{*}{$\begin{array}{c}\text { One-step } \\
\text { mixing }\end{array}$} & $\begin{array}{c}60 \\
\text { rotations }\end{array}$ & & & & - & 1 & 3 \\
\hline & & $\begin{array}{c}80 \\
\text { rotations }\end{array}$ & & & & & - & 4 \\
\hline & $\begin{array}{c}\text { Gradual } \\
\text { mixing }\end{array}$ & $\begin{array}{c}60 \\
\text { rotations }\end{array}$ & & & & & & - \\
\hline
\end{tabular}

Data shown in Fig. 1 were statistically analyzed to determine the difference in mixing degrees obtained by using various preparation methods. The shaded area represents the comparison between the powdered and crystallized lactose. A comparison of the mixing degrees obtained by one-step mixing of powdered lactose followed by 60 rotations and gradual mixing of crystallized lactose followed by 60 rotations revealed that there is a significant difference between the $\mathrm{CV}$ values for four kinds of triturations (4-, 8-, 16- and 32-fold triturations), and the number of four is therefore indicated in the corresponding position of this table. Other numbers in this table should be read as exemplified above.

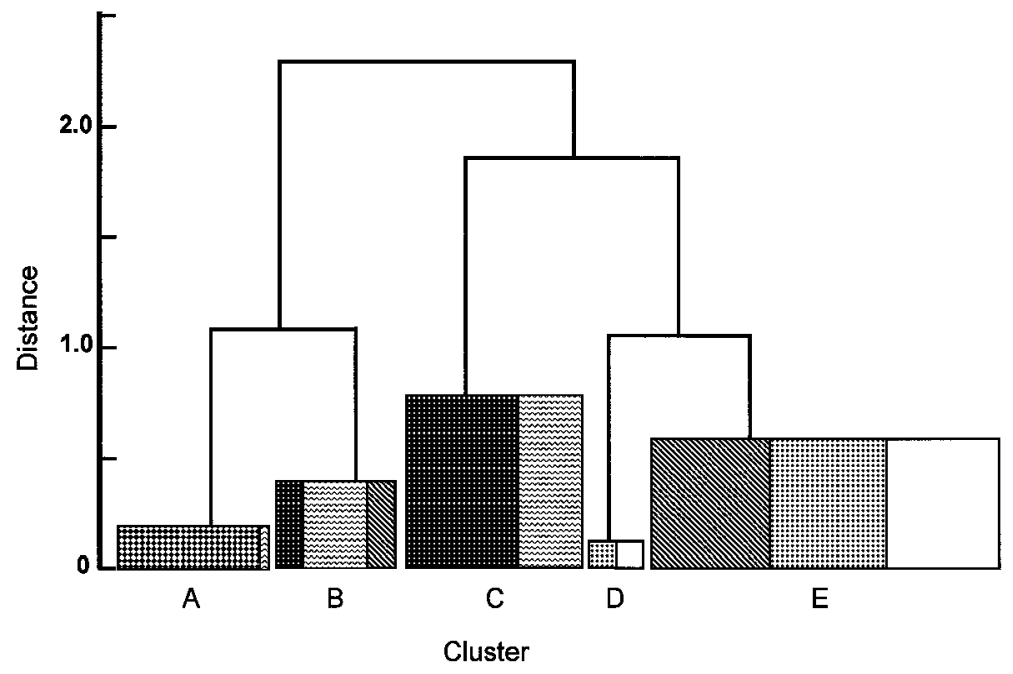

Fig. 2. Cluster Analysis of the Mixing Degree

Data shown in Fig. 1 were subjected to cluster analysis. The figure shows the mixing degrees after one-step mixing of powdered lactose followed by 60 rotations

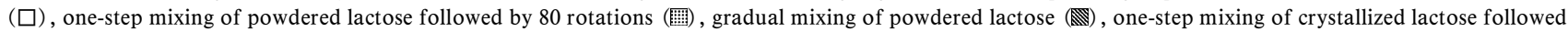

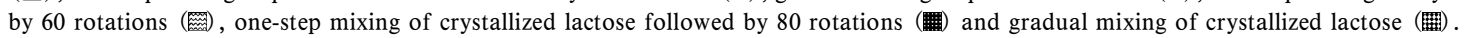

lactose. The results of cluster analysis indicated that there was no significant difference between the mixing degrees of powdered lactose obtained by using the two mixing methods, since the mixing degree of these two groups belong to the same cluster (cluster E; Fig. 2). Moreover, the Euclidean distance between cluster $\mathrm{D}$ and cluster $\mathrm{E}$ was small, suggesting similarity between these two clusters (Fig. 2). In contrast, for crystallized lactose, particularly for crystallized lactose mixed gradually, where the mixing degree belonged to cluster A, the Euclidean distance was far from clusters D and/or E (Fig. 2). For the powdered lactose and the crystallized lactose, mixing degrees obtained after 60 rotations and after 80 rotations in the one-step mixing method seemed to be similar, since the results of these two rotations belonged to the 
Table 4. Summary of Cluster Analysis

\begin{tabular}{|c|c|c|c|c|c|c|}
\hline \multirow{3}{*}{ Cluster } & \multicolumn{3}{|c|}{ Powered lactose } & \multicolumn{3}{|c|}{ Crystallized lactose } \\
\hline & \multicolumn{2}{|c|}{ One-step } & \multirow[b]{2}{*}{ Gradual } & \multicolumn{2}{|c|}{ One-step } & \multirow[b]{2}{*}{ Gradual } \\
\hline & $\begin{array}{c}60 \\
\text { rotations }\end{array}$ & $\begin{array}{c}80 \\
\text { rotations }\end{array}$ & & $\begin{array}{l}60 \\
\text { rotations }\end{array}$ & $\begin{array}{c}80 \\
\text { rotations }\end{array}$ & \\
\hline A & & & & 0 & & (0) \\
\hline B & & & $\bigcirc$ & (2) & $\bigcirc$ & \\
\hline $\mathrm{C}$ & & & & 0 & (2) & \\
\hline $\mathrm{D}$ & $\bigcirc$ & $\bigcirc$ & & & & \\
\hline $\mathrm{E}$ & (0) & (2) & (2) & & & \\
\hline
\end{tabular}

Data shown in Fig. 2 were summarized in this table. () and $\bigcirc$ represent the main and sub clusters, respectively. For example, cluster A consists of one-step mixing with 60 rotations and gradual mixing of crystallized lactose. In addition, it is indicated that the gradual mixing of crystallized lactose is the main cluster of cluster A.

same cluster (Fig. 2).

Decrease in Erythrocin Concentrations in Triturations The ratio of the observed concentrations of erythrocin in the triturations divided by the expected concentrations are shown in Fig. 3. Up to 32-fold triturations, the observed concentration/expected concentration ratio ranged from 0.9 to 1.3 regardless of the kind of diluents and mixing method (Fig. 3). In contrast, in 64-fold triturations, the ratios were approximately 0.8 for all preparation methods used in the present study (Fig. 3).

\section{DISCUSSION}

As $69.7 \%$ and $50.5 \%$ of the colored lactose and powdered lactose passed through the 200-mesh sieves (screen size of $74 \mu \mathrm{m}$ ) respectively, accurate estimation of the distribution of particle sizes by sieving method was not possible. In addition to this method, we determined the particle distribution patterns by using the laser diffraction method and found that there was no significant difference between the particle sizes of the colored lactose and powdered lactose (Table 2 ). The difference between the $d_{50}$ values obtained by using the two determination methods was due to the fact that aggregated particles did not pass through the sieves, whereas no aggregation took place in the laser diffraction method since the spray method was used in the latter determination. It was also found that less than $20 \%$ of crystallized lactose had a particle diameter of less than $74 \mu \mathrm{m}$, whereas most of the colored and diluent lactose had particle diameters of less than $74 \mu \mathrm{m}$.

Preparation of 4- to 64-fold triturations of colored lactose with either powdered lactose of the same par- ticle size or crystallized lactose resulted in excellent mixing, with CV values of less than $6.08 \%$, regardless of the mixing method (Fig. 1).

Comparison of the results obtained after 60 rotations and 80 rotations in the one-step mixing showed that there was no correlation between $\mathrm{CV}$ values and number of rotations (Fig. 1). The results of our preliminary experiments in which the number of rotations was set at 20, 40, 60, 80 and 100 times showed demixing phenomena; that is, the CV value was lower in the case of 40 rotations than in the case of 20 rotations, but it increased or decreased as the number of rotations was increased (unpublished observations). These results suggest that the minimal difference between the $\mathrm{CV}$ values in the case of 60 rotations and that in the case of 80 rotations (Fig. 1) may result from the large degree of demixing.

A comparison of the mixing degrees of powdered and crystallized lactose indicated that a satisfactory mixing degree was obtained for the powdered lactose by using either mixing method, whereas significant large variation was observed in the crystallized lactose for the mixing degrees (Fig. 1). One reason of the difference between the mixing degrees of the powdered and crystallized lactose might be that the latter was prepared to have a broader particle size distribution and largeer particle size. Indeed, 40, 19 and 17\% of crystallized lactose was trapped by the sieves with 100, 150 and 200 mesh, respectively, and $24 \%$ passed through the sieve with 200 mesh, which was different from the particle size distribution of the powdered lactose. In addition, for the powdered lactose, the results of cluster analysis suggested that there was no difference between the mixing degrees obtained by us- 

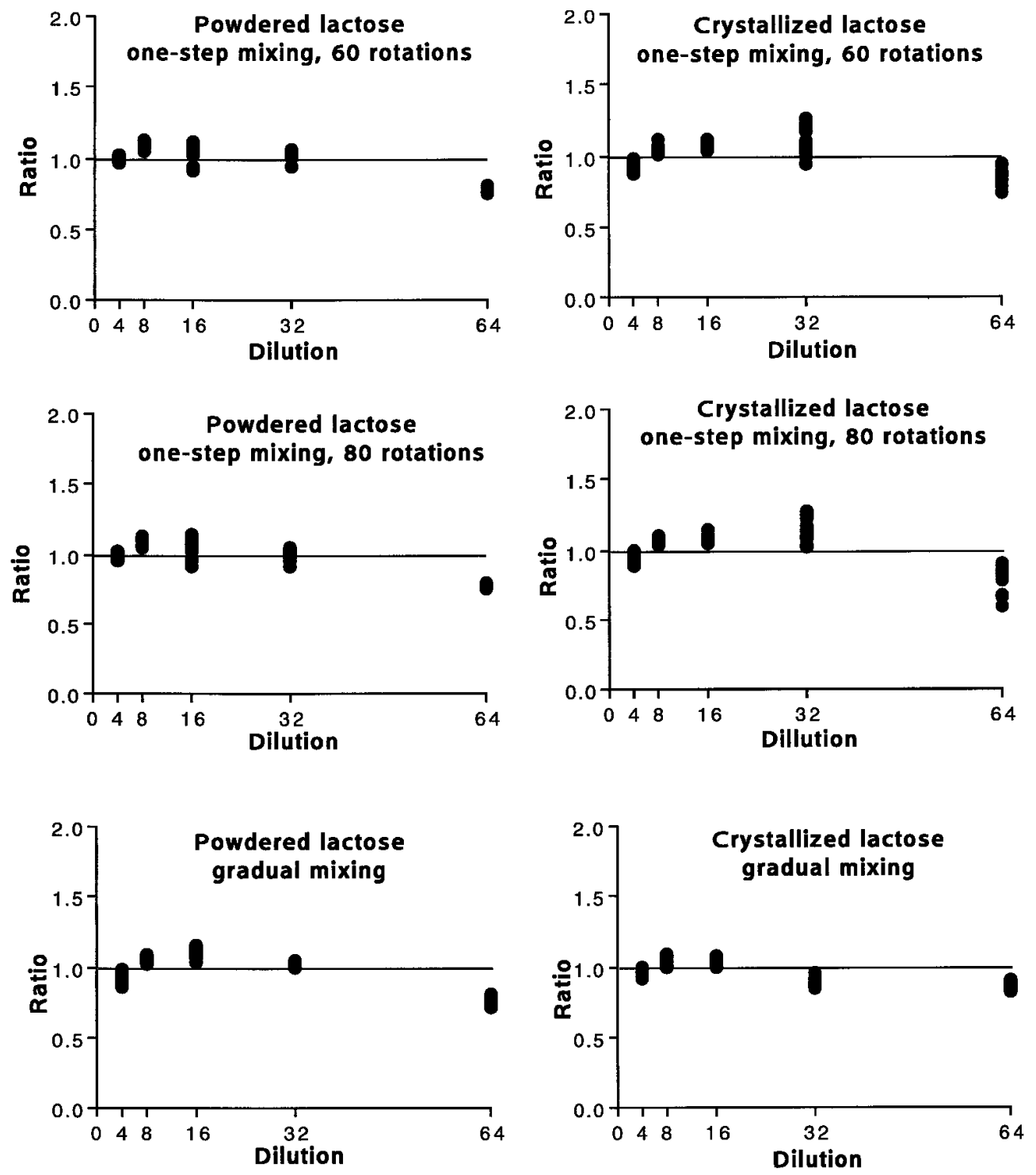

Fig. 3. Decrease in Erythrocin Concentrations in Triturations

The observed/predicted concentration ratios of erythrocin were determined after mixing of powdered and crystallized lactose by the one-step and gradual mixing methods.

ing the one-step and gradual mixing methods due to the fact that these two preparation methods belonged to the same cluster (Fig. 2). In contrast, for the crystallized lactose, the one-step and gradual mixing methods belonged to different clusters (Fig. 2). These results suggest that there was a clear difference between the mixing character of powdered lactose and that of crystallized lactose. Moreover, the mixing degrees obtained by using the one-step mixing of crystallized and powdered lactose followed by 60 and 80 rotations were categorized into different clusters; the different number of rotations of crystallized lactose resulted in clusters $B$ and $C$, whereas that of powdered lactose resulted in clusters D and E (Fig. 2).
These results may be accounted for by considering the phenomenon of demixing.

It was also revealed that the concentration of erythrocin in the 64 -fold trituration was $80 \%$ of the expected value (Fig. 3). Studies on digoxin concentrations in 1,000-fold triturations indicated that the digoxin content was $12 \%$ less than the predicted value, ${ }^{14)}$ this difference being due to adsorption of the drug to the mortar and pestle (Fig. 3). It is possible that erythrocin was adsorbed to the apparatus used in the present study. Since the effect of adsorption of principal agents became significant for triturations with high rates of dilution, it was thought that triturations with more than 64- and 100-fold dilutions were 
associated with decreases in the concentrations of principal agents.

From these findings, it was demonstrated that an excellent degree of mixing, with $\mathrm{CV}$ values of less than $6.08 \%$, was obtained for triturations of up to $64-$ fold dilution regardless of whether one-step or gradual mixing was used. However, for the preparation of triturations of agents whose therapeutic drug monitoring was required, it is necessary to prepare wellmixed triturations with minimal $\mathrm{CV}$ values. For the preparation of triturations of such agents, physicality must be considered. Moreover, since drug adsorption to the mortar and pestle in the case of extensive dilution (such as more than 64-fold dilution), it is necessary to examine the concentrations of agents after preparation of triturations.

\section{REFERENCES}

1) Okada J., Matsuda Y., Morita S., Wada Y., Ohnishi H., Yakugaku Zasshi, 88, 827-831 (1968).

2) Okada J, Matsuda Y., Fukumori Y., Yakugaku Zasshi, 92, 270-274 (1972) .

3) Awada E., Ohtsuka K., Morioka T., Ikegami Y., Yakuzaigaku, 19, 141-144 (1959).

4) Ueno T, Saito M., Suzuki A., Yakuzaigaku, 19, 244-247 (1959).
5) Sakurai Y., Fujii S., Ito, S., Yakuzaigaku, 16, 7-12 (1956).

6) Aoki M, Fukuda T., Ueda S., Mochizuki A., Yakuzaigaku, 27, 106-108 (1967).

7) Nakamura H., Higo K., Suzuki A., Fujinuma Y., Tanaka Y., Ohtani M., Kotaki H, Iga T., Jpn. J. Hosp. Pharm., 23, 306-311 (1997) .

8) Tanno K., Watanabe K., Morikawa E., Yakuzaigaku, 31, 112-117 (1971) .

9) "The Japanese Guidelines for Dispensation (10th ed),"” ed. by Japan Pharmaceutical Association, pp. 42-45.

10) "Annotation to The Japanese Guidelines for Dispensation," ed. by Editorial Board for the Annotation to The Japanese Guidelines for Dispensation, Yakujinippou-sha, 1997, pp. 150-157.

11) Kozatani J., Kitaura T., Ashida K., Yakuzaigaku, 29, 53-56 (1969) .

12) Ueda S., "Cluster Analysis," Asakura Shoten, Tokyo, 2003.

13) Koyano W., "Multivariate Analysis," Kawashima Shoten, Tokyo, 2001, pp. 147-150.

14) Mizutani Y., Tomioka K., Adachi N., Matsuno T., Kawai S., Ishizuya O., Medicine \& Drug J., 28, 2205-2208 (1992). 